\title{
Escribir y traducir en el Sur. A propósito de las relaciones entre feminismo y marxismo en la Argentina de los años 70 \\ Writing and translating in the South. About the relations between feminism and Marxism in Argentina in the 1970 s
}

Alejandra Ciriza

Universidad Nacional de Cuyo - Argentina

Mendoza, Argentina

aciriza@mendoza-conicet.gob.ar

Eva Rodríguez Agüero

Universidad Nacional de Cuyo - Argentina

Mendoza, Argentina

evarodriguezaguero@gmail.com

\section{RESUMEN}

Este trabajo analiza el arraigo diferencial de las ideas feministas en el sur en los años 60 y 70 poniendo en cuestión el énfasis eurocéntrico de algunas teorías que leen los feminismos del Sur como producto del retardo en la recepción de ideas acuñadas en el norte desconsiderando las condiciones efectivas de existencia, las tensiones Norte/Sur, las diferencias y desigualdades entre blancas y racializadas, entre burguesas y proletarias, entre heteronormadas y disidentes sexuales y corporales. A partir de la búsqueda y revisión de textos traducidos y producidos en Argentina durante esos años, traza un panorama de los debates teóricos de la época recuperando a la vez el carácter internacional y situado. Ubicados en el campo de disputa entre feminismo y marxismo, esas controversias tensionaban a la vez los límites de las perspectivas patriarcales de las izquierdas y los límites de clase de ciertos feminismos.

Palabras clave: feminismos del sur; feminismo; marxismo; escritos; traducciones

\section{ABSTRACT}

This work analyzes the differential rooting of feminist ideas in the South in the 1960s and 1970s, questioning the Eurocentric emphasis of some theories read by Southern feminists as a product of the delay in the reception of ideas coined in the North, disregarding the effective conditions of existence, the North/South tensions, the differences and inequalities between white and racialized women, between bourgeois and proletarian women, between heteronority and sexual and corporal dissidence. Based on the search and review of texts translated and produced in Argentina during those years, it draws a panorama of the theoretical debates of the time, recovering at the same time the international and situated character. Located in the field of dispute between feminism and Marxism, these controversies stressed both the limits of the patriarchal perspectives of the left and the class boundaries of certain feminisms.

Keywords: feminisms from the south; feminism; Marxism; writings; translations 


\section{Introducción}

Los feminismos atraviesan fronteras, encarnan en sujetos ubicados en coordenadas diversas tanto temporales como espaciales y corporales. De allí la importancia de ubicarlos atendiendo a las determinaciones de las formaciones sociales en las que emergieron; a las articulaciones específicas entre economía, política y cultura que los hicieron posibles en cada formación social; a las líneas de conflicto de clase, racialización, corporalidad; a las relaciones de colonialidad; a las tradiciones políticas y culturales que demarcaron sus horizontes en cada momento histórico.

Este escrito se ocupa de trabajar sobre esas maneras diferenciales de arraigar poniendo en cuestión una anticipación de sentido que lee los feminismos del sur a partir de un patrón, una suerte de paradigma tácito acerca de qué cosa sea ser feminista que privilegia el modelo emancipacionista y occidentalizante. En esa perspectiva el feminismo es, como alguna vez señalara Hobsbawm, producto de occidente, entendiendo por tal Europa y Estados Unidos. Los feminismos situados en otras coordenadas son producto de la influencia, el reflejo, la copia más o menos desvaída o distorsionada de ese original inalcanzable para mestizas, negras, indias, proletarias y un largo etcétera.

A contrapelo, este escrito procura por genealogías feministas/de mujeres en las periferias, feminismos ubicados en tensión, cercados por distorsiones, desajustes temporales, malos entendidos y desacuerdos, propios de esas zonas de cruce que Silvia Rivera Cusicanqui ha denominado chixi: el punto en el cual la dominación patriarcal se cruza con la dominación colonial, el nudo entre traducir y traficar teorías, el hueco por el cual ingresa un luz a la vez que arroja potentes sombras. Atiende al modo en que producir ideas, traducciones y debates feministas se inscribe en ciertas condiciones de existencia marcadas por las tensiones entre las mujeres del norte y las del sur, entre blancas y negras, entre burguesas y proletarias, entre heteronormadas y disidentes sexuales y corporales. Pregunta por las traducciones, no como simples traslados de lengua, sino como procesos sociales y políticos que tienen puntos en común pero también puntos de fuga. Algo así como inconmensurabilidades vinculadas a las condiciones de existencia de quienes escriben, quienes traducen, quienes leen.

Desde la perspectiva que sostenemos en este trabajo, los años 70's del siglo pasado fueron una coyuntura singular, iluminada por diversas tentativas de tomar el cielo/el propio cuerpo por* asalto, que involucró a los sectores subalternos, a colonizados y colonizadas, a mujeres europeas y estadounidenses sumidas en la mística de la femineidad blanco-occidental, a personas racializadas, proletarios y proletarias, disidentes sexuales que en el sur formaban parte de organizaciones que luchaban contra el coloniaje, por lo que entonces se nombraba como "la patria socialista”, o lisa y llanamente, la revolución'.

Se apunta a realizar un seguimiento de los debates teóricos que, en los años 60 y 70, pusieron en diálogo feminismos y marxismo. Se hará recuperando traducciones de amplia difusión y un libro compilado por Mirta Henault, probablemente el primer libro feminista publicado en Argentina por aquellos años (Andújar et al., 2005)². De manera no casual esos escritos se hallan ubicados en el campo de discusión de las izquierdas en un momento histórico en el cual el espectro político se inclinaba en esa dirección, lo cual no quita, claro, que hubiese posiciones reaccionarias. Incluso quienes procedían de otras orientaciones políticas se encontraban envueltas/os por un cierto aire de época, una estructura del sentir como le llama Williams, propia de ese momento de condensación del tiempo33.

Tras la dictadura las feministas dialogaron con el campo de los derechos humanos y la democracia. Las cuestiones del Estado, la ciudadanía, los derechos, se convirtieron en el centr de las preocupaciones mayoritarias en un contexto de reflujo de las izquierdas, de retroceso de los sectores populares y de

1 El caso del Frente de Liberación Homosexual (FLH) es en este sentido emblemático (Rapisardi \& Mondarelli, 2001, p. 172).

2 Es interesante señalar que en 1972 vio la luz un libro publicado por editorial Humanitas, cuyo compilador fue Ezequiel Ander Egg titulado Opresión y marginalidad de la mujer en el orden social machista. Incluye trabajos de Ander Egg, Norma Zamboni, Anabella Yañez, Jorge Gissi y Enrique Dussel, que fueron resultado de las conferencias y seminarios realizados en la ciudad de Mendoza en el Instituto de Acción Social y Familiar (Ander Egg et al., 1972).

3 Esos años estuvieron marcados por la expectativa de la revolución. Se había producido una oportunidad para subvertir el orden social establecido. Esos momentos podrían ser considerados bajo la categoría de kairós, estos es, momentos de condensación del tiempo, lo que Benjamin llamaba un Jet Zeit, una ocasión para una praxis política colectiva que modifica la experiencia del mundo y la percepción del tiempo. En orden a la cuestión del tiempo, el de las revoluciones anuda y condensa la temporalidad, son un momento singular en el que se produce una oportunidad de transformación abrupta del viejo orden, aun cuando ello pueda suceder de manera efímera. Como señala Marx en El dieciocho brumario de Luis Bonaparte, los procesos revolucionarios sintetizan pasado, presente y futuro, lo dado y lo por venir, produciendo tensiones y relaciones inesperadas (Ciriza, 2013). 
ascenso de la democracia como forma de legitimación del orden político.

Este escrito trabaja sobre la estructura de sentimiento de ese tiempo a la vez denso y fugaz entre fines de los 60 y los tempranos 70 y hace eje en el diálogo/las controversias entre feminismo y marxismo a través de la revisión de textos y traducciones que circularon por entonces en Argentina.

\section{Breves notas sobre una estructura del sentir: anticolonialismo, mujeres, sexo e izquierdas}

La segunda mitad del siglo XX, tras la segunda guerra interimperialista, fue un momento de intenso internacionalismo desde abajo. Un momento cruzado por la tentativa, en varios países colonizados, de seguir la estrategia de Dienh Bien Puh expulsando a los colonialistas de los territorios ocupados, y marchando hacia formas socialistas de organización social (Fanon, 1973). Coincidió con un ciclo largo de la economía capitalista internacional durante el cual hubo crecimiento económico permanente y pleno empleo (Mandel, 1972).

Por aquellos años se escuchaban las voces de las batallas por la independencia de los países del sureste asiático, la marcha hacia el socialismo emprendida en Cuba tras el triunfo de la Revolución, la batalla descolonial en Argelia. Estos procesos alcanzaron dimensión internacional y estuvieron marcados, como sucede en tiempos de revoluciones, por la intensa presencia de miles de mujeres. Ellas empezaron a formar parte, de manera creciente, de la fuerza de trabajo y los sindicatos, ingresaron a las universidades en mayores proporciones (Palermo, 1998) y asumieron grados altos de participación en las organizaciones políticas, incluidas las armadas (Martínez, 2008; Grammático, 2011). Asimismo, asuntos específicos como el derecho al aborto y la denuncia de la violencia contra las mujeres, la discusión sobre diversas formas de discriminación y cosificación, la pregunta por la organización del parentesco, la indagación por las relaciones entre patriarcado y capitalismo, el cuestionamiento de la doble moral sexual y el goce de la propia sexualidad pasaron a ocupar un espacio creciente en los debates intelectuales y políticos, claro que con acentos muy diversos.

Si en Europa y Estados Unidos la presencia pública de mujeres y disidentes sexuales con demandas propias se canalizó a través de movimientos liberacionistas en un momento de honda crisis de los partidos comunistas y de emergencia de un abanico de preocupaciones que incluían la paz, el consumo, el lugar de las mujeres y la discriminación racial; las del sur: árabes, africanas, vietnamitas, latinoamericanas, participaron de otras maneras en los canales generados a partir de los puntos de fractura abiertos por la lucha anticolonial y el horizonte del socialismo. Los feminismos en Nuestra América fueron arraigando en las condiciones de vida de las mujeres, en la politización creciente de dimensiones de sus vidas hasta ese momento naturalizadas: la división sexual del trabajo, la escisión entre la vida pública y la privada, las formas de organización familiar, el proceso de separación entre sexualidad y reproducción, la heterosexualidad compulsiva, la violencia, la maternidad.

En ese terreno de visibilidad de las mujeres, vinculada a las transformaciones en las condiciones materiales de existencia que tan bien describe Mandel (1972), interesa recuperar las producciones escritas por feministas en territorio argentino y atender a las traducciones como una suerte de nudo, de espacio de internacionalización de debates a la vez que de diálogo y confrontación norte/sur ${ }^{4}$. La cuestión del trabajo doméstico devino un asunto central en ese momento histórico, que precipitó en la organización de una campaña internacional por un salario para las amas de casa del que formaron parte María Rosa Dalla Costa y Selma James, Silvia Federici, Margaret Benston, las integrantes del Socialist Workers Party y la canadiense Peggy Morton. La cuestión preocupaba a feministas y militantes en nuestras tierras, como puede leerse en los valiosos aportes de Isabel Larguía, en las observaciones de Mirta Henault, y en la demanda impulsada por organizaciones de mujeres ligadas a las izquierdas que procuraban el establecimiento de jardines maternales y un salario para las amas de casa (Dos Santos, 1983).

Muchos de los escritos leídos, debatidos, traducidos y producidos por entonces se sitúan en un campo de tensiones entre feminismo y marxismo, pues algunas feministas y algunas marxistas estaban preocupadas

\footnotetext{
4 Mandel indica que el capitalismo tardío, en esa inflexión histórica, fue acompañado por un proceso de centralización técnica y económica. Técnicamente, una creciente división del trabajo sólo puede combinarse con la creciente socialización del proceso de trabajo por medio de una extensión de funciones intermedias: de allí la expansión sin precedentes de los sectores del comercio, el transporte y los servicios. La mecanización, la estandarización, la superespecialización y la parcelación del trabajo, que en el pasado determinó sólo el dominio de la producción de mercancías en la industria propiamente dicha, penetra en todos los sectores de la vida social. Esos procesos tuvieron un doble efecto sobre las vidas de las mujeres: reemplazo de lo que se produce en casa por mercancías que exigen una creciente salarización y presión para incorporarse al mundo del trabajo asalariado (Mandel, 1972).
} 
por hallar respuesta a la pregunta por la relación entre capitalismo y patriarcado tensionando los límites de las perspectivas patriarcales sostenidas por las izquierdas y los límites de clase de ciertos feminismos.

Tal vez sea difícil desde el horizonte de lectura actual imaginar que alguna vez el entonces denominado Tercer Mundo estuvo en el centro de las preocupaciones políticas e intelectuales de quienes habitábamos estas latitudes, y también, lo que resulta más asombroso, de los/las metropolitanos/as. Si Margaret Randall y Otilia Vainstok seleccionaron los trabajos que integraron las dos compilaciones de traducciones más reconocidas en Argentina, existe otra compilación, mucho menos conocida, consistente en la traducción de un número especial de la revista Partisans dedicado al naciente Mouvement de Libération des Femmes (MLF) bajo el título Libération des femmes, année zéro. La traductora fue Susana "Pirí" Lugones5. El asunto de Partisans es interesante porque la revista había incluido un trabajo escrito por la argentino-cubana Isabel Larguía, "Contre le travail invisible", y un escrito de Anne Zélensky sobre la situación de las mujeres cubanas. Según Bellucci y Teumer fue Zélensky quien invitó a Larguía a escribir para Partisans y suya la idea de que la autoría fuese exclusivamente de Larguía (Bellucci y Teumer, 2018). Partisans se proponía como un espacio de debate acerca de las luchas emancipatorias y las perspectivas de los países de lo que entonces se denominaba tercer mundo.

\subsection{Mujeres en el amplio abanico de las izquierdas. El sexo en cuestión}

La importancia de los nexos entre feminismos e izquierdas, entre feminismo y marxismo, obedece a una correlación de fuerzas (tanto en el nivel internacional como latinoamericano) propia de esa coyuntura. Ese clima de agitación e inquietud social y política se inscribió en un ciclo histórico marcado por una serie de transformaciones en las condiciones materiales de vida que impulsaron a las mujeres al mercado de trabajo y conmovieron las bases de las relaciones familiares: la necesidad de otro salario puso en crisis la naturalización de la división sexual del trabajo, a la vez que la posibilidad de contar con anticoncepción hormonal generó transformaciones en las prácticas y perspectivas sobre la sexualidad, que devino asunto de controversia pública.

Lo cierto es que no solo se había producido la descolonización de la antigua Indochina. Argelia y muchos países africanos se habían visto conmovidos por las luchas de liberación mientras en América Latina un ciclo ascendente de procesos revolucionarios, por decirlo en los términos de Kossok (1983), hacía temblar el orden establecido. En ese contexto muchas mujeres se sumaron a diversas formas de práctica política, desde el activismo estudiantil hasta la incorporación a organizaciones político-militares. También se sumaron con voz propia a distintos espacios de debate intelectual y contribuyeron a pensar algunos dilemas de la tradición marxista, como el de las relaciones entre capitalismo y patriarcado, la división sexual del trabajo, el lugar de las mujeres en los procesos revolucionarios.

En Nuestra América dos acontecimientos contribuyeron a la apertura del horizonte político hacia la cuestión del socialismo: las experiencias cubana y chilena. En Argentina se conjugaban agitación política y movilización obrera en el contexto del segundo ciclo de sustitución de importaciones (Basualdo, 2006).

Participación política, ingreso al mercado de trabajo y a las universidades se combinaron para impulsar a las mujeres, muchas de ellas muy jóvenes, a intervenir activamente en la lucha política en un momento que es señalado, desde muchas perspectivas y en distintas latitudes, como fundacional para la historia de las mujeres y feministas. En Argentina llegaron a ser una parte importante, incluso desde el punto de vista porcentual, de las organizaciones guerrilleras integrando distintas fuerzas políticas: las Fuerzas Armadas Peronistas (FAP) y Montoneros, que contó con una organización de mujeres, la Agrupación Evita, el Partido Revolucionario de los Trabajadores (PRT) y su brazo armado, el Ejército Revolucionario del Pueblo (ERP). Bajo la iluminación de las transformaciones sociales en curso las demandas mujeriles cobraron cuerpo incluso en el debate electoral. Algunos partidos, como el Partido Socialista de los Trabajadores (PST), de orientación trotskista, llevó como candidata a Nora Ciapponi e incorporó reivindicaciones específicas en su plataforma electoral. El asunto también formaba parte de las discusiones en el Frente de Izquierda

\footnotetext{
5 Susana Lugones, conocida como Pirí (1925-1978) era nieta del poeta Leopoldo Lugones e hija del torturador del mismo nombre. Estudió en la Facultad de Filosofía y Letras de la Universidad de Buenos Aires donde conoció a Carlos Peralta, que fue el padre de sus tres hijos. Pirí fue escritora, traductora, militante. Era famosa por las fiestas que hacía en su departamento, en el edificio de El Hogar Obrero en el barrio porteño de Caballito, donde se reunían Noé Jitrik, Osvaldo Lamborghini, Quino, León Rozitchner, Tanguito, el Tata Cedrón, Jorge Álvarez y Daniel Divinsky, entre otros. Con estos últimos se lanzó a la vida como editora. En 1959 viajó a Cuba y a su regreso colaboró con la agencia cubana de noticias Prensa Latina. Escribió para Noticias entre 1973 y 1974 y militó en FAP y Montoneros. Fue amiga y compañera de militancia de Paco Urondo, Juan Gelman y Rodolfo Walsh, con quien convivió un tiempo. Fue secuestrada por la Armada Argentina durante la última dictadura militar, en 1977, torturada en la ESMA y asesinada durante un traslado en febrero de 1978 (Baschetti, 2018; Seoane, 2014).
} 
Popular (FIP) (Vassallo, 2005, pp. 19-38). Muchas de esas mujeres, desde luego Ciapponi, pero también Alicia Eguren, Pirí Lugones, Susana Gaggero encarnaron modelos transgresores de feminidad tanto en lo político como en su vida personal (Seoane, 2014).

Hijas de su tiempo, algunas feministas argentinas, como María Elena Walsh, se ubicarán brevemente en una cierta proximidad con la izquierda sin perder su inspiración en el Women's Lib (Walsh, 1973). Inclusive María Elena Oddone, la célebre editora de Persona, llegó a participar en 1972 de una actividad promovida por el PST a través de la organización Muchacha ${ }^{6}$. Esto ocurrió durante la visita a Argentina de la entonces candidata a la presidencia de Estados Unidos por el Socialist Workers Party (SWP), la feminista y socialista Linda Jenness, que en ese año se hallaba de gira por el país. Desde luego que esa participación no hizo rumbo en la trayectoria de Oddone, cuya abierta hostilidad hacia la izquierda está fuera de toda discusión?.

En cuanto a la sexualidad, también es preciso procurar por la diferencialidad de los acentos. No sólo se trató de las investigaciones de Masters y Johnson, o las de Alfred Kinsey, ni del debate contra la tradición puritana, tal como se produjera en Estados Unidos. Tal vez sea preciso preguntarse por las diferentes direcciones en que discurrió el asunto en un contexto impregnado por otras determinaciones respecto de la maternidad, la heterosexualidad compulsiva, la experimentación amorosa y erótica, la propuesta de formas más libres de vivir el propio cuerpo y la pareja. La preocupación creciente por las prácticas anticonceptivas, no sólo era parte de decisiones individuales, sino de políticas estatales y de las relaciones norte/sur, como el célebre Plan Mac Namara.

La propuesta de la Alianza para el Progreso implicaba en forma explícita la apelación al control de la natalidad pues, como dijera Kennedy en su discurso del 13 de marzo de 1961 convocando a la Alianza para el Progreso:

El crecimiento de la población sobrepasa al desarrollo económico; los niveles de vida, bajos de por sí, se ven aún más amenazados y crece el descontento, el descontento de un pueblo que sabe que por fin está a la mano la abundancia y los instrumentos de progreso (Kennedy, 1961, p. 3).

El Estado argentino asumió una respuesta contundente: el 28 de febrero de 1974, en un decreto - $\mathrm{N}^{0} 659-$ firmado por Juan Perón y el ministro de Bienestar Social, José López Rega, se disponía el control de la comercialización y la venta de productos anticonceptivos por medio de la presentación de una receta por triplicado y la prohibición de desarrollar actividades relacionadas con el control de la natalidad.

A la vez que las intervenciones de esterilización compulsiva generaban rechazo, las feministas agrupadas en UFA defendían el uso de anticonceptivos (Vassallo, 2005; Felitti, 2012). Si por una parte se expandía un clima liberacionista que procuraba por una nueva moral sexual para las mujeres y lo que entonces se denominaba "homosexuales", por la otra se hizo cada vez más frecuente la incorporación y utilización de alusiones sexuales en la publicidad y la construcción del mito de la "mujer moderna" como sustituto del ideal de ama de casa y mujer doméstica de los años 50 . El uso de sugerencias sexuales en la propaganda fue (y es aún) una herramienta central del capitalismo en el proceso de incorporación de las masas al consumo.

Los debates sobre sexualidad, anticoncepción y aborto fueron ocupando lugar en la agenda pública. En el norte, entre las mujeres blancas, el escenario se abrió a la conquista del derecho al aborto; en el sur primó 6 Persona fue una revista feminista que conoció dos períodos. Durante el primero se publicaron seis números entre septiembre de 1974 y
fines de 1975 . Vinculada al Movimiento de Liberación Femenina, reunía a un puñado de mujeres: Lía Conde, Ester Block, Mary Dávila, Victoria
Mungo, Susana Sías Moreno, Paula Cobos y la fotógrafa Alicia D'Amico para el primer número; Susana Sías Moreno, Diana Cobos, Ester Block,
Valeria Capo, Victoria Mistral, María del Carmen Vázquez y en fotografía, diagramación y dibujos, Sara Facio, Alicia D’Amico, Sara Torres, Lía
Conde y Silvia Bruno para el segundo número; Roberto Domichovsky, María del Cármen Vázquez, Luis Rinaldi y las fotografías de Alicia D’Amico,
Carlos Campos y Sara Facio para el tercer y cuarto número. Los números cinco y seis son menos cuidados en la edición y más reducidos en
tamaño. El último tiene apenas veinte páginas. Persona estuvo fuertemente marcada por la impronta de María Elena Oddone, una mujer de
clase media, exesposa de un oficial de la Aeronáutica, que decía de sí misma que se trataba de construir un "nosotras las mujeres" por encima
de las divisiones de clase. Intransigente, frontal, convencida de la justeza de su punto de vista, Oddone relata su vida en un libro autobiográfico
escrito en 2001 (Oddone, 2001).

7 Oddone no duda en decir, en una entrevista con Perlongher, lo siguiente: “Ideológicamente estaba en desacuerdo con ellas [las integrantes del Frente de Lucha de la Mujer, formado en 1975] y se enojaron porque no acepté un refugio que me ofrecieron: el frente era un grupo de apoyo a la izquierda subversiva. Si yo no estaba en eso ¿por qué me iba a autoexiliar?" (Oddone, 2001, p. 164). 
la alerta ante las intervenciones imperialistas en procura del control poblacional (Felitti, 2012), e incluso algunas advertencias a propósito de la única forma de libertad tolerable para el capitalismo: la libertad sexual (Larguía, s.f.).

Bajo la conjetura de que Las mujeres dicen iBasta! condensa esa estructura de sentir es que se convoca a su recuperación y relectura.

\section{Las mujeres dicen basta. Lecturas marxistas sobre el lugar de las mujeres}

Coordinado y editado por Mirta Henault merced una incipiente editorial que llamaron Nueva Mujer, un pequeño grupo de mujeres en proceso de devenir feministas publicó, en el año 71 , Las mujeres dicen basta, un libro que constituye un emblema de la época y un interesante revelador de la especificidad del feminismo en nuestras tierras: a la vez que instancia de diálogo con las izquierdas y crítica de sus prácticas y perspectivas limitadas en lo referido a las reivindicaciones de las mujeres, el texto da muestra de las estrategias de diálogo internacionalista con orientaciones políticas afines a la editora del libro, Mirta Henault.

Henault venía de una larga militancia trotskista. Desde principios de los años cincuenta había integrado las filas de Palabra Obrera y militado en sindicatos a partir de su experiencia como obrera textil y metalúrgica. En 1964 su compañero, el 'Vasco' Bengochea, había muerto mientras manipulaba explosivos en un episodio ocurrido en la calle Posadas que tuvo amplia repercusión, y convirtió a Henault en una "paria política" (Vassallo, 2005).

La obra incluye tres artículos, uno de autoría de la propia compiladora, "La mujer y los cambios sociales", que contiene reflexiones acerca de las tensiones entre feminismos e izquierda (Henault, s.f., pp. 13-40), uno de Isabel Larguía, titulado “La mujer” (Larguía, s.f., pp. 71-128), y la traducción de un trabajo de Peggy Morton realizada por Regina Rosen y titulado "El trabajo de la mujer nunca se termina" (Morton, s.f., pp. 41-70). Este último texto había sido publicado en el periódico feminista Leviathan. Morton formaba parte del Communist Party of Canada-Marxist Leninist, y había participado de acciones realizadas por estudiantes canadienses en contra de la guerra de Vietnam.

La idea general del libro es producir un análisis capaz de dar cuenta de la situación de las mujeres como seres biológicos en la maternidad; como reproductoras de la fuerza de trabajo en sus tareas domésticas; como trabajadoras en el proceso de producción social y como seres sexuados. Al considerar la dimensión sexual y la maternidad, el trabajo doméstico y el trabajo asalariado, las autoras buscan exceder la célebre tesis de que la subordinación de las mujeres no era otra cosa que una contradicción propia del capitalismo que se resolvería de un modo sencillo una vez que adviniera el socialismo.

\subsection{Mirta Henault, un cambio en la manera de mirar}

El breve escrito de Henault, "La Mujer y los cambios sociales" (Henault, s.f., pp. 13-40) nace, como ella misma señala, de la necesidad de reflexionar acerca de la organización de un movimiento de mujeres que, poniendo en cuestión la tradición marxista, encare la lucha por su propia liberación sin abandonar los ideales del socialismo. Sus reflexiones proceden de la tensión entre la formación recibida, la experiencia militante y el impulso de las lecturas del escrito de Mitchell, Las mujeres, la revolución más larga y El Segundo sexo, de Simone de Beauvoir (Henault, 2012).

Henault indaga en la especificidad de la posición de las mujeres en el orden social señalando las dificultades de la respuesta beauvoiriana que, en su interpretación, presenta la situación de inferiorización de las mujeres como si fuese atemporal. En diálogo con la tradición marxista ubica las claves en el terreno de la historia y en los efectos de la división sexual del trabajo: si las mujeres son lo otro es porque "han sido condicionadas por exigencias sociales que... son el reflejo de su ubicación en la base económica sobre la cual se sustentan esas relaciones sociales" (Henault, s.f., p. 14). La situación de las mujeres obedece a su confinamiento: al producir objetos para el consumo diario, su trabajo, que es no acumulativo, genera una suerte de detención en sus conciencias. Mientras los varones avanzan ellas permanecen explotadas y dominadas a causa de las imposibilidades para transformar su mundo y sus propias condiciones de vida (Henault, s.f., p. 16). En la división sexual del trabajo se halla la clave del estancamiento de las mujeres, de su apoliticismo, de su tendencia a rehuir instancias de participación (partidos y sindicatos) que les han sido históricamente ajenas, pues han sido construidas según lógicas políticas extrañas a sus vidas y 
posibilidades.

En una clave muy próxima a las de las preocupaciones del movimiento que en los años 70 reclamaba un salario para el ama de casa, Henault lee la situación de las mujeres a partir del análisis de Engels: la división sexual del trabajo y la producción de bienes de uso han condenado a las mujeres a posiciones subalternizadas. Ese análisis se complementa con la lectura del texto de Mitchell que circulaba en aquellos años en la compilación de Margaret Randall (Randall, 1969). El tono de la introducción general del libro, la sugerencia de atender a diversas dimensiones para interpretar el lugar de las mujeres en la sociedad, la inquietud por revisar los aciertos y errores en los procesos revolucionarios, dan cuenta de un cambio en la forma de mirar a la vez que de una intensa preocupación por la dirección asumida por las izquierdas.

Henault, pasa revista a los procesos de las revoluciones rusa y china y concluye que las revoluciones no han cumplido sus promesas emancipatorias para la mitad de la humanidad. A la manera como lo hiciera Mitchell, destaca las limitaciones de las visiones que la izquierda ha sostenido sobre las mujeres, pues a la vez que necesita de su aporte revolucionario escamotea sus reivindicaciones. La mayor parte de los revolucionarios se ha limitado a insistir en la incorporación de las mujeres a la producción, y en la idea de que con el socialismo el problema de las mujeres se resolverá. Sin embargo, su alienación milenaria exige una respuesta específica. La idea de que lo personal es político, de que la transformación de la condición de las mujeres debe considerar la vida cotidiana, alienta en la caracterización que Henault va desgranando a lo largo de su escrito: algo en el orden de lo no teorizado insiste en las dificultades para la liberación de las mujeres, la repetición de lo siempre igual afecta a ese sector detenido cuya labor, centrada en la producción de bienes de uso, genera una conciencia no acumulativa.

La especificidad de la vida cotidiana, su tendencia a la repetición, reclama una perspectiva específica, pues los cambios que se han producido (la incorporación de las mujeres al mercado de trabajo, e incluso la liberalización de las costumbres) no han terminado con los viejos mitos que sobreviven en una suerte de tiempo quieto. Las formas de opresión cambian, pero no la opresión misma. De allí que deberán ser las mujeres mismas quienes protagonicen la transformación de la sociedad desde sus propias bases procurando por la humanización de la naturaleza humana (Henault, s.f., p. 17).

Comprometida en la crítica de la psicologización o biologización de la inferiorización de las mujeres, Henault ve en la emancipación mujeril la clave para el salto cualitativo que hará lugar a la historia, arrasando con los límites que tanto la propiedad privada como el cambio en el régimen social no han logrado sobrepasar.

Si la revolución de octubre había removido prejuicios y barreras en aras de la socialización del cuidado y de la resolución colectiva de la reproducción de la vida, si los años posteriores al asalto del palacio de invierno habían barrido con las leyes que impedían el divorcio, y el reconocimiento de los derechos de las personas homosexuales, Rusia, señala Henault, "se ha transformado en un país de costumbres retrógradas donde los tabúes sexuales, los prejuicios más anquilosados destruyen la creatividad de las mujeres y asfixian sus aspiraciones" (Henault, s.f., p. 27). El caso chino podía presentarse auspicioso en algunos aspectos, pero tampoco en China la revolución había transformado las condiciones de vida. Según Henault "las mujeres existen en función de madres, de esposas o de compañeras (...) Pero ellas no han logrado ser seres humanos autónomos. Todavía conservan la dependencia patriarcal de la cual no se han desprendido" (Henault, s.f., p. 30). La revolución cubana, por su juventud, centelleaba como una promesa hacia el futuro.

Afinidades y distancias la unían a su tradición: las herramientas de lectura, como la de división sexual del trabajo, la recuperación de los procesos revolucionarios y la crítica de sus límites, bajo el signo de las expectativas abiertas hacia un futuro que excediera las revoluciones hasta ahora conocidas, una revolución capaz de escuchar a las mujeres más allá de la familia y la propiedad privada, una revolución que atendiera a sus deseos de autonomía, que escuchara algo en orden a las transformaciones en las relaciones sexuales, la consideración del placer y la sexualidad.

3.2 Isabel Larguía: para una crítica de la naturalización de la división sexual del trabajo. De cómo la familia y la apropiación privada del trabajo de las mujeres son las claves de bóveda de su inferiorización

Si bien en la secuencia del libro el trabajo de Morton ocupa el segundo lugar, por su relevancia y agudeza en la relectura de los efectos de la división sexual del trabajo sobre la vida de las mujeres, y el lugar de la 
propia Larguía en la trama de escritura y traducción, conviene hacer lugar a su escrito, cuyo título en esta compilación es La mujer (Larguía, s.f.).

Según señalan Dumoulin y Larguía en un texto posterior (1988), comenzaron a escribir en 1967 una versión del ensayo,

...publicada por Partisans en 1970 con el título “Contra el trabajo invisible” y luego en Buenos Aires por Mirta Henault en Las mujeres dicen basta por la editorial Gránica. En esos años aparecieron unas veinte ediciones en Cuba, en diversos países de América Latina y de Europa, y en los Estados Unidos (Larguía \& Dumoulin, 1988, p. $8)^{8}$.

Inspirado en una genealogía marxista y en los textos clásicos, el escrito dialoga con El origen de la familia, la propiedad privada y el Estado y con La ideología alemana como sus fuentes de inspiración y claves de lectura, a la vez que destaca las reflexiones políticas anticipadas por Lenin en Una gran iniciativa (1919). También lo hace con el escrito de Margaret Benston, The political economy of women's liberation, publicado en 1969 por The Monthly Review (Larguía, s.f., p. 77), un texto que también retoma Peggy Morton y que es considerado como uno de los escritos fundamentales en el debate marxista-feminista de los años 70 's.

Larguía proporciona un argumento fundamental para la caracterización del lugar de las mujeres en la economía capitalista, a la vez que ilumina los mecanismos a través de los cuales se atribuye a la biología lo que es efecto de las relaciones sociales. La desnaturalización de la familia y el desbrozamiento del jeroglífico social que atribuye a la naturaleza las causas de la división sexual del trabajo permiten explicar los mecanismos sociales a través de los cuales se invisibiliza la contribución de las mujeres a la reproducción del orden social capitalista. La negación del valor económico del trabajo llevado a cabo por las mujeres (la reposición directa de la fuerza de trabajo) alimenta una confusión ideológica y "encubre uno de los fundamentos más antiguos y persistentes de la sociedad de clases” (Larguía, s.f., p. 72).

En consonancia con el argumento engelsiano, Larguía sostiene que, lejos de estructurarse en arreglos amorosos y funciones domésticas derivadas de la biología, la familia es la base de la propiedad, pues a través de su organización el pater familiae tiene la posibilidad de disponer de la fuerza de trabajo de otros. Solo a partir de la emergencia de la familia patriarcal la vida social quedó dividida en dos esferas nítidamente diferenciadas: la pública y la doméstica (Larguía, s.f., p. 73).

La separación analítica de las actividades que llevan a cabo privadamente las mujeres en el seno de la familia, a) la reproducción estrictamente biológica, b) la educación y cuidado de los hijos, enfermos y ancianos, c) la reproducción de la fuerza de trabajo consumida diariamente, revela su carácter históricosocial (Larguía, s.f., p. 73). La consideración del conjunto del proceso de trabajo permite percibir que, al reponer privadamente la fuerza de trabajo, las mujeres contribuyen a la economía capitalista. Sin embargo, el carácter privado asignado a ese trabajo, el hecho de que produzca bienes de uso y la atribución de un carácter biológico a lo que no es sino trabajo privado determinado por la división sexual del trabajo, hace que este permanezca invisibilizado como trabajo y como aporte económico de las mujeres. A través de esa operación el trabajo del ama de casa es transformado en una suerte de emanación de la naturaleza mujeril. Si el mundo se ve invertido es que lo está: el trabajo doméstico es percibido como si se tratase de "caracteres sexuales secundarios" pues esa naturalización encubre el carácter social de la división sexual del trabajo.

De la misma manera que en las sociedades capitalistas las mercancías van al mercado por sus propios medios, del mismo modo en que se produce un efecto de inversión que hace de la mercancía un sujeto y del sujeto que lo produce un objeto, los efectos de la división sexual del trabajo son vistos como la causa del lugar de las mujeres en la sociedad, lo social deviene natural y el trabajo doméstico es atribuido a las mujeres como si se tratase de una capacidad derivada de la biología.

Tras los pasos de la lectura marxiana del fetichismo de la mercancía (Marx, 1973), Larguía desmenuza

8 En la información proporcionada por la/el autor/a hay un error: la versión publicada por Henault lleva por título "La Mujer", y la editorial es Nueva Mujer. El libro publicado por Granica es una traducción, hecha artículo por artículo por Pirí Lugones, de la revista editada por Maspero. En esa edición el texto efectivamente se titula "Contra el trabajo invisible". 
los mecanismos a través de los cuales la división sexual del trabajo consolida tipologías contrapuestas y biologiza el lugar de las mujeres, pues de su capacidad para gestar se deriva su responsabilidad por la continuidad biológica y social de la especie. Sobre ese efecto de inversión se monta el romanticismo:

...la más formidable cortina de humo que pudo segregar la historia para ocultar la explotación de fuerza de trabajo esclava. El regordete Cupido que revoloteaba en torno a nuestras abuelas fue en realidad el más efectivo gendarme al servicio de la propiedad privada (Larguía, s.f., p. 92).

La consolidación de tipologías sexuales opuestas se entrelaza, en la lectura de Larguía, con la referencia a una serie de procesos ligados al desarrollo del capitalismo: la disolución de los antiguos lazos, que ubican el contrato como figura central de la sociedad burguesa haciendo de cada sujeto un individuo capaz de vender su fuerza de trabajo y de ingresar en diversos contratos ${ }^{9}$. Si las mujeres pueden elegir libremente con quién casarse, la asignación de las funciones reproductivas produce efectos sobre su incorporación a la clase obrera. No solo se trata de sus salarios, sino de las tareas que se les asignan, y de la invisibilización de la sobrecarga de la segunda jornada de trabajo.

Larguía observa que el reforzamiento de las tipologías sexuales tiende a fortalecer la ligazón entre mujeres y sexo. Los efectos de tal reforzamiento no dejan de ser paradojales pues, bajo el signo del capital monopolista y de la mercantilización de todos los aspectos de la vida, el sexo deviene, precisamente, la mercancía más valiosa de que disponen las mujeres. En una clave de lectura proporcionada por los debates acerca de las características del capitalismo en el período de posguerra, Larguía advierte que la persistencia del capitalismo es perfectamente compatible con la libertad sexual y la mercantilización del sexo. El sexo puede ser utilizado sin dificultad para aumentar el consumo en una fase del capitalismo en la cual es decisivo incentivarlo.

Precisamente: en el espacio del sexo las libertades individuales sobreviven. En una sociedad dominada por el monopolio, los hombres comprueban que el liberalismo pequeñoburgués ha dejado de corresponder por completo a la realidad económica y política. El sexo es el único terreno donde el liberalismo sigue desarrollándose activamente. División sexual del trabajo, mercantilización de todos los aspectos de la vida y liberalismo pequeño burgués se conjugan de modo tal que el sexo ocupa un lugar cada vez más relevante pues las mujeres, a diferencia de los varones, no disponen fácilmente de su fuerza de trabajo para vender, pero sí pueden disponer de su sexo.

El diagnóstico de la situación abre las puertas para la crítica de las alternativas que se presentan ante los ojos de las mujeres: su reclusión en los estrechos asuntos del sexo muestra vías ilusorias de emancipación que las encadenan a la condición de objeto sexual. La manipulación del sexo ofrece alternativas que no son sino formas de permanecer dentro de los marcos del orden establecido. Desde su punto de vista el liberalismo sexual "al estilo de la propuesta de Wilhem Reich" (Larguía, s.f., p. 108) que preconiza la emancipación sexual desligándola de la lucha de clases, y el economismo femenino "que captura a las mujeres en el mundo del consumo potenciando el individualismo generado por el aislamiento de las amas de casa" (Larguía, s.f., p. 108) son salidas individualistas que no producen transformaciones reales del orden social.

Las vías reales para la emancipación derivan, según Larguía, del diagnóstico realizado: tras los pasos de Engels, supuesto que la familia monogámica y patriarcal fue la clave para la apropiación privada del trabajo de las mujeres y de la pérdida del valor social de su trabajo, que resulta invisibilizado pues se lleva a cabo en un espacio separado de la vida pública del trabajo y la política, solo su supresión liberará a las mujeres, que de esa manera podrán reincorporarse a la industria social. La emancipación de las mujeres no transita por el camino de la lucha por libertades misérrimas en los marcos establecidos por la moda y los consumos en la sociedad capitalista, sino por la disolución de la familia como unidad económica. Entre la Escila de una emancipación puramente sexual e individualista que preserva los valores de la competencia y la Caribdis de la mera incorporación de las mujeres a la producción, Larguía señala la relevancia de una

9 Demás está insistir sobre la densidad teórica del planteo de Larguía, y sobre la cantidad de asuntos que han sido retomados en los debates feministas actuales. Es notoria la crítica del contractualismo y su sentido pretendidamente emancipatorio en el conocido texto de Carole Pateman (1985). 
perspectiva compleja capaz de erradicar el individualismo pequeño-burgués y sobrepasar la naturalización de la división sexual del trabajo, que ha consolidado la reproducción de la fuerza de trabajo como trabajo invisible y fatalidad "biológica".

El texto se cierra apelando al modelo de la federación de mujeres cubanas, una organización de masas nacida en el seno de la revolución para propugnar la igualdad y la participación política de las mujeres en el proceso revolucionario y al heroico ejemplo de las vietnamitas, a la vez que pone en cuestión los patrones clasistas de belleza y la utilización de las mujeres por parte de los medios de comunicación masiva, que promueven la difusión de la imagen de la mujer-sierva y de la mujer-mercancía.

Indudablemente en el trabajo de Larguía la cuestión de la sexualidad no tiene la fuerza argumentativa que tiene en el escrito de Mitchell (1969). Dice Mitchell:

Los socialistas han compartido la consigna de abolición de la familia burguesa... pero la preocupación debería ser la igualdad entre los sexos y no la abolición de la familia... La igualdad no surgirá de aboliciones administrativas sino de transformaciones históricas. Deberían ser criticadas las campañas contra la homosexualidad en Cuba. Es importante su legalización, y debería ser apoyada porque es una de las formas de sexualidad no reproductiva. También se debería abogar por la libre distribución de anticonceptivos y se debería abolir la idea de ilegitimidad pues permite separar parentalidad de matrimonio (Mitchell, 1969, p. 102).

Larguía tampoco comparte plenamente las preocupaciones de Henault. Mientras Henault da relevancia a la libertad sexual, la rosarina se ubica en sintonía con las preocupaciones centrales de la tradición marxista: la crítica de la división sexual del trabajo y la abolición de la familia. Ubica en cambio la cuestión de la sexualidad en el terreno del combate anticapitalista: contra la creencia en que la emancipación sexual conducirá a la revolución socialista. Larguía se ocupa de revelar la trama que inscribe la emancipación sexual en la lógica capitalista. Si el socialismo no terminará con el patriarcado de manera inmediata y automática, el sexo libre no abrirá las compuertas de la revolución.

\subsection{Peggy Morton: la cuestión del trabajo doméstico, un debate de proyección internacional. Pensar desde el horizonte de la práctica política}

Morton comparte con Larguía el interés por hallar en la economía capitalista claves interpretativas para la lectura de la opresión de las mujeres. Es preciso, desde su perspectiva, desentrañar las funciones psicológicas, económicas y políticas de la familia como un lugar de opresión y explotación de las mujeres.

Si le creyésemos a Mitchell, las marxistas recorren con paciencia recurrente los senderos trazados por la tradición: la crítica de la familia y de los efectos de la división sexual del trabajo. Y es que la familia no es solo el lugar que aprisiona a las mujeres en la tarea de reposición y educación de la mano de obra requerida por la sociedad en cada momento histórico (Morton, s.f., p. 41), sino que también proporciona a los varones un lugar para descargar su violencia y desahogar sus sentimientos de frustración e ira. A contrapelo de las perspectivas que leen la familia como unidad de consumo, Morton retoma el trabajo de Maggie Benston, quien señala que la función primordial de la familia no consiste en ser una unidad de consumo, sino que es la base económica para la opresión de las mujeres: las mujeres son, en los hogares privados, trabajadoras sin salario. El aislamiento al que están sometidas no es sino uno de los aspectos centrales de su opresión, y una de las dificultades para su organización política.

En diálogo con Benston, Morton procura responder a los interrogantes que ésta deja abiertos: es preciso pensar la articulación entre el trabajo doméstico y el trabajo asalariado, establecer las conexiones que permitan interpretar las relaciones entre el lugar de las mujeres en el mercado de trabajo y la asignación de responsabilidades domésticas, indagar en los nexos entre su opresión en cuanto mujeres y su explotación en razón de la clase social.

Desde la perspectiva de Morton la potencialidad revolucionaria de las mujeres descansa en que la 
mayor parte de ellas están oprimidas como mujeres y explotadas como trabajadoras. Es por ello que las estrategias a seguir no solo deben apuntar a las convicciones abstractas, sino que deben estar basadas en las necesidades reales de las mujeres y en la determinación precisa de las contradicciones existentes.

De allí que se deba establecer un diagnóstico cabal de las transformaciones históricas de la familia por su doble función psicológica y política, sexual y económica. Morton pasa revista a las funciones de la familia como unidad de producción durante el medioevo, los cambios habidos en los tiempos inaugurales del capitalismo y los nuevos, bajo el capitalismo avanzado, marcados por la necesidad de reproducir mano de obra especializada (Morton, s.f., pp. 49-52). La familia desempeña un papel nodal en la incorporación de la autodisciplina, en la internalización de las relaciones jerárquicas, en la presión para prolongar la permanencia en la escuela y en la represión de la sexualidad.

El circuito del aumento del consumo ha incidido sobre la creciente necesidad del salario de las mujeres: “(...) el porcentaje de mujeres trabajadoras ha crecido de un $27.7 \%$ en 1961 a un $34.4 \%$ en 1968 (en Canadá) ha aumentado el promedio de familias que cuentan con ingresos de las esposas" (Morton, s.f., p. 54).

Las familias se han reducido en tamaño al compás de la presión que ejerce la desocupación, la baja de salarios, el mandato de permanecer en la escuela. La reducción en el tamaño es una tendencia que permanecerá, pues ha ido aumentando la libertad sexual fuera del matrimonio y existe un mayor acceso al control de la fecundidad (Morton, s.f., p. 58). Sin embargo, aun cuando sea verdad que las mujeres constituyen el ejército de reserva y están sujetas a un número mayor de horas de trabajo, también lo es que el combate contra la familia y su crítica abstracta no generará un movimiento de masas, pues la mayor parte de las personas consideran a la familia como "el único lugar donde las necesidades básicas emocionales pueden ser satisfechas" (Morton, s.f., p. 65).

Preocupada por la construcción de un movimiento masivo, Morton propone colocar la mirada en las contradicciones objetivas que llevan a las mujeres a "una mayor conciencia de opresión", e incita a la construcción de un movimiento masivo que no se deje tentar por posibles soluciones que solo llegan a unas pocas. De la misma manera que sucede con Larguía, incluso si sus posiciones políticas no son exactamente las mismas en el amplio abanico de las tradiciones de izquierda, Morton apuesta a la construcción de un feminismo socialista y proletario, atento a las necesidades de las mujeres desde la perspectiva de un partido que es a la vez internacionalista y socialista.

Las posiciones de las autoras reunidas en la publicación hablan de quien editara el libro, de su tránsito por la izquierda, de su inscripción en la tradición trotskista, de la larga afinidad que ligó a Henault con Palabra Obrera y la revolución cubana, pero fundamentalmente de los debates que estaban entonces a la orden del día, con sus matices y variaciones desde luego, pero cruzados por esa suerte de aire de familia tan diferente del que habitara los debates de los ochentas. Eso que Williams hubiese llamado "estructura del sentir".

\section{Traducciones. Notas sobre tráficos y traducciones}

No es un dato menor que editoriales como de la Flor y Siglo XXI se embarcasen en la aventura de publicar readers en los cuales circulaba lo más desafiante de las teorías feministas recientes, producidas al calor del Women's Lib en Estados Unidos.

Ediciones de la Flor, dirigida por Daniel Divinski, había sido creada a partir de una iniciativa de Jorge Álvarez, con la complicidad de Pirí Lugones. Desde Ediciones de la Flor y bajo la responsabilidad de Otilia Vainstok se publicó Para la liberación del segundo sexo (1972). Poco tiempo antes Margaret Randall compiló Las mujeres (1970), probablemente uno de los libros sobre feminismo más leído en el período, que además circuló a lo largo y ancho de Nuestra América ${ }^{10}$. A ello se suma un tercero: La liberación de la mujer: año cero, bastante menos recordado, publicado por Editorial Granica.

Los textos incluidos por Vainstok, todos ellos sumamente sugerentes, contemplaban escritos colectivos e individuales. Desde asuntos como prostitución, tratado por Susan Brownmiller, un escrito sobre la "política del orgasmo", de Susan Lydon, y uno sobre el amor entre mujeres de Anne Koedt, hasta una

10 Durante las Jornadas de Historia de las Mujeres llevadas a cabo en Buenos Aires desde el 24 al 27 de julio de 2017 se leyó una primera versión de este trabajo. Formaban parte de la mesa Marisa Navarro, Ana Lau Jaiven, Mónica Tarducci, Mary Goldsmith y alejandra ciriza. Para todas ellas las primeras lecturas latinoamericanas de escritos feministas estadounidenses habían sido los textos traducidos a iniciativa de Randall, que condensaban los debates vivientes en la época. 
crítica al psicoanálisis de Shulamith Firestone y una selección del libro de Kate Millet, "Política Sexual", de reciente aparición. Roxanne Dunbar y Margaret Randall discurren por el carril de las relaciones entre feminismo y revolución a través de sendos textos: "La Liberación Femenina como base de la Revolución Social" y "La conciencia es una prioridad". Particularmente estimulante resulta "Una declaración sobre Liberación Femenina", que convoca a las mujeres a incorporarse a la lucha contra el sexismo en nombre de una organización "que abarca todos los aspectos de la lucha feminista incluidas la educación y las actividades de concientización alrededor de las demandas básicas del movimiento como el cuidado de los hijos, el aborto e iguales salarios" (Vainstok, 1972, p. 188).

La contratapa es desafiante: sobre fondo negro y recuadro blanco, en mayúsculas y letras fucsia hay una presentación que, tras una cita de Engels procedente de El origen de la familia, la propiedad privada y el Estado, señala el largo tiempo para que las mujeres, "las víctimas de esa opresión tomaran conciencia de ella", y los procesos a través de los cuales el movimiento feminista ha sido "folklorizado" reduciendo su lucha a "la liberación de los senos y la quema de soutiens en la plaza pública". Los revolucionarios latinoamericanos, se advierte, "menosprecian al movimiento concediéndole, en todo caso, un rol secundario o ulterior a la lucha por la liberación nacional". La selección incluye "las más brillantes representantes del movimiento de liberación femenina norteamericano" con vistas a orientar "el sentido que esa lucha puede asumir para las mujeres en un país dependiente" (Vainstok, 1972). Para Vainstok la clave se hallaba en poner en cuestión la trivialización del feminismo por parte de la izquierda revolucionaria de entonces a partir del modelo proporcionado por el movimiento feminista estadounidense, en un momento en el cual las preocupaciones de la mayoría de ellas discurrían alrededor de las luchas anticoloniales y las críticas del militarismo y el racismo. Vainstok publicaría un año después, en el emblemático Centro Editor de América Latina, un librito escrito en colaboración con Mirta Henault titulado La mujer en la revolución (1973), que trabaja sobre la relación histórica entre los procesos revolucionarios y las mujeres, desde la francesa a las revoluciones socialistas, incluidas la rusa, la china, la cubana y la vietnamita y una breve consideración sobre la relación entre mujeres y peronismo. También analiza, aun cuando brevemente, el asunto de la división sexual del trabajo.

La traducción de Lugones dialoga con un mundo cultural diferente: el del Mouvement de Libération des Femmes, inscripto en la tradición francesa vinculada a Beauvoir, al reciente combate por el derecho al aborto, a las intervenciones de la propia Beauvoir, Gisèle Halimi y Sartre en la disputa por la descolonización de Argelia. Partisans, la revista editada entre 1961 y 1973 por François Maspero, un reconocido librero y editor parisino, publicó un número doble (54-55) titulado Libération des femmes, année zéro.

Partisans no era cualquier revista". La publicación era una tribuna de las luchas anticoloniales pues Maspero las consideraba como un momento central en la historia política del mundo, una inflexión a partir de la cual los pueblos de todos los colores reclamaban su lugar en el coro de la humanidad (Guichard et al., 2009).

La traducción, llevada a cabo por Pirí Lugones y publicada por Editorial Granica en el marco de la colección Libertad y Cambio, que dirigía Eduardo Goligorsky, reúne en formato libro los mismos trabajos publicados por Partisans: un escrito de Kathy Mac Afee y Mynna Wood, "Pan y rosas", uno de Margaret Benston que hemos registrado como una referencia relevante en el debate sobre el trabajo doméstico, retomado por Larguía y Morton; uno de Roxanne Dunbar, "La casta y la clase, una clave para comprender la opresión de las mujeres" (Rochefort et al., 1973, pp. 47-53). La compilación incluye un muy conocido escrito de Naomi Weisstein, “Kinder, Küche, Kirche como ley científica. La psicología construye a la mujer”, que también forma parte del reader realizado un par de años antes por Margaret Randall (1970). El artículo de Weisstein, publicado originalmente en 1968, apuntaba a mostrar que la psicología carecía de herramientas para comprender a las mujeres, pues se limitaba a producir teorías sin fundamento científico sobre la base de las cuales se consolidaban los prejuicios sociales existentes, a saber: que la biología destina a las mujeres a la maternidad, el matrimonio y la domesticidad. Para Weisstein no hay diferencias inmutables entre varones y mujeres, y hasta tanto la sociedad no ofrezca respeto igual, las respuestas de ambos sexos no harán sino reflejar los prejuicios sexistas existentes. Dos textos notables, uno de Christine Delphy'2,

11 El primer comité de redacción de Partisans reunía en torno de Maspero a Marie-Thérèse Maugis, Maurice Maschino, un conocido periodista y militante por independencia argelina, el historiador Pierre Vidal-Naquet, entre otros y otros colaboradores. Maspero tenía un hondo compromiso con la izquierda y las luchas anticoloniales. Escribieron en Partisans Fidel Castro, el Che Guevara, Amilcar Cabral, Ahmed Ben Bella. Contribuyeron Ernest Mandel, Paul Sweezy, Leo Huberman, entre otros.

12 Por entonces Christine Delphy firmaba sus escritos como Dupont. 
“El enemigo principal", y una versión de la elaboración de Isabel Larguía respecto del trabajo invisible en el proceso de reproducción de la fuerza de trabajo en beneficio del capital, insisten sobre el asunto de la división sexual del trabajo. También se puede leer un artículo de la escritora y activista feminista Christiane Rochefort sobre la frigidez femenina y varios que abordan la militancia, incluido uno sobre la revolución cubana firmado por Anne Z. y titulado "La revolución en la revolución en Cuba", una suerte de balance de la situación de las mujeres cubanas tras la revolución que tomara el poder en enero de 1959.

En 1969 se había publicado en México Las mujeres, precedido de un prólogo de Margaret Randall, quien por entonces se hallaba en tránsito entre México y Cuba'3. Randall presenta, en su "Introducción", una selección de escritos desde los cuales ofrece herramientas interpretativas para la lucha feminista (Randall, 1970, pp. 9-22). Próxima a las izquierdas revolucionarias del continente, Randall ubica diferentes posiciones para la lucha feminista. Mientras algunas luchan "por su total liberación y la de sus hermanas", y otras, "más reformistas", pertenecen a grupos mixtos batallando por "más centros de atención infantil, por la revisión de las leyes sobre aborto y el control de la natalidad, por salarios más altos y oportunidades laborales iguales para las mujeres, por la organización de hermanas contra el servicio militar y la guerra” ella se identifica con quienes "ven la Revolución, correctamente, como una lucha de clases (mi tesis) pero que ven como parte integral de la lucha la necesidad de una verdadera liberación de su sexo" (Randall, 1970, p. 10).

Como la mayor parte de los escritos del período, refiere a la perspectiva engelsiana sobre la división sexual del trabajo como la primera forma de división del trabajo. Para ella la socialización de los medios de producción y la conversión del trabajo doméstico, el cuidado y la educación de los hijos en un asunto social son la clave de la liberación de las mujeres. Si los países socialistas no han logrado un avance significativo para las mujeres, la revolución sexual sin conciencia política no las emancipará. En cuanto "único grupo oprimido [que es] absolutamente necesario en la historia", las mujeres deben asumir colectivamente la tarea de reflexionar acerca de las condiciones políticas de su subordinación desde un horizonte feminista y socialista:

En Cuba, después del asesinato de Ernesto Guevara un pueblo entero gritó al unísono: ¿Cómo queremos que sean nuestros hijos? iComo el Che! Para el Che Guevara la creación de un hombre nuevo era esencial para el proceso revolucionario. Me apasiona una revolución en la que sean esenciales tanto un hombre nuevo como una mujer nueva (Randall, 1970, p. 21).

El libro reúne "Kinder, Kuche, Kirche como ley científica...”, también incluido en la selección traducida por Pirí Lugones y "El consumidorismo de las mujeres" un escrito de Ellen Willis, una feminista radical estadounidense, periodista e integrante de un grupo llamado Redstockings en alusión a las bluestockings inglesas del siglo XVIII y a la proximidad ideológica de las integrantes del grupo con la izquierda. Para Willis la teoría de la manipulación psíquica de las mujeres por parte de los medios de comunicación de masas tiene sus raíces en los prejuicios de clase, sexo, raza y su pronta aceptación por parte de las personas radicalizadas, incluyendo mujeres.

Una Declaración del grupo pro-liberación femenina de Nueva York da cuenta de las tensiones entre feministas e izquierda, entre la "liberación de las mujeres" y la lucha antirracista. La supremacía masculina es denunciada como un privilegio difícil de remover pues no solo se trata de la forma más antigua de dominación, sino de que "las mujeres son los únicos oprimidos cuyas vidas están totalmente vinculadas a las de sus opresores... Las mujeres debemos construir una conciencia radical específicamente femenina” (Randall, 1970, p. 48).

El asunto de la concienciación es tratado por Irene Peskikis, mientras la "política de las tareas domésticas" es analizada a través del recurso a la propia experiencia (y el humor) por Pat Mainardi, quien insiste en subrayar los efectos políticos y cognoscitivos de la falta de involucramiento de los varones en tareas que

13 Margaret Randall es una poeta, escritora y fotógrafa estadounidense que vivió muchos años en España, México, Cuba y Nicaragua. Residió en Vietnam del Norte durante el último mes de la invasión norteamericana a ese país. En 1969 se hallaba en Cuba. Según sus propias palabras "quería entender qué quiere decir una revolución socialista para las mujeres, qué problemas puede resolver y cuáles permanecen irresueltos" (Zuckerman, 1987, p. 13) 
históricamente han sido llevadas a cabo por las clases y razas consideradas inferiores y por las mujeres.

El testimonio de Dunbar narra su experiencia de parir y maternar una niña sin fontanela. Sometida a una operación riesgosa la niña murió. La lúcida y descarnada descripción de la situación hace visibles los efectos del paternalismo médico, la soledad y aislamiento de las mujeres ante el parto y el puerperio, la crianza, la muerte.

Tras este grupo de textos se encuentra un escrito que alcanzó intensa difusión y que es referido, entre otras, por Mirta Henault: "Las mujeres, la revolución más larga", de Juliet Mitchell, un artículo extenso que debate al interior de la tradición marxista (Randall, 1970, pp. 67-104). Para Mitchell una paradoja caracteriza la situación de las mujeres: el ser fundamentales y marginadas a la vez. Ello ha ocasionado dificultades, pues si bien la teoría marxista, en términos generales, reconoce el lugar central de las mujeres en los procesos de naturalización y hominización de los seres humanos, pues la "relación del hombre con la mujer es la relación más natural del ser humano con el ser humano" (Mitchell, 1970, p. 70); y en sus escritos juveniles Marx señala la familia burguesa como la base práctica sobre la cual la burguesía ha construido su dominio, pues sienta las condiciones que hacen de un burgués lo que es, instaurando relaciones de propiedad y exclusividad (Mitchell, 1970, p. 70), el filósofo alemán pasa de manera abrupta de formulaciones filosóficas generales a comentarios históricos. Entre ambos modos de tratamiento hay, según la marxista inglesa, una grave disyunción.

Para ella "el lugar que ocupa el problema de las mujeres en la obra de Marx y Engels es subsidiario de la discusión sobre la familia" (Mitchell, 1970, p. 72), a la vez que ese análisis instituye un nexo determinante entre familia y propiedad privada estableciendo un acento economicista en las propuestas emancipatorias. O bien ideal normativo no integrado a la teoría socialista, o bien posición economicista, los marxistas no han comprendido la clave de la inferiorización de las mujeres pues los argumentos han sido ubicados en una presunta debilidad corporal que impide percibir la coerción, que se ubica en una clave política más que económica. Es la debilidad social, no la debilidad corporal lo que convierte a las mujeres en esclavas.

Las estrecheces de la tradición se deben a limitaciones teóricas y a la dificultad para percibir que la emancipación de las mujeres involucra cuatro estructuras: producción; reproducción de la especie humana (incluida la maternidad); sexualidad (signada entre los marxistas por el conservadorismo del propio Marx), y socialización de la prole. La preocupación de Mitchell no refiere únicamente al conservadorismo histórico de los socialistas en lo referido al sexo, sino a las campañas contra la homosexualidad vigentes en la Cuba de esos años. Desde su punto de vista el socialismo debería conducir a la diversificación de las relaciones sociales como "un logro humano en el largo paso de la naturaleza a la cultura, que es la definición de la historia y la sociedad" (Mitchell, 1970, p. 104).

Varios textos hacen referencia a situaciones específicas: el de Joan Jordan, a la situación de las mujeres norteamericanas; el de William Hinton, a la liberación de las mujeres en la China revolucionaria, y el de Jorge Risque Valdés, ministro de trabajo de Cuba, a la experiencia de incorporación de mujeres al trabajo productivo en la isla durante la plenaria nacional de la Federación de Mujeres Cubanas, en 1968. El texto de Jordan es particularmente interesante, pues para ella la clave está en la explotación laboral, de modo tal que negras y blancas deberían salvar el abismo que separa a los trabajadores negros y blancos organizándose sobre la base del sexo y reunificando a la clase trabajadora. En su concepción el capitalismo es incompatible con la liberación de las mujeres. Su análisis, minucioso y determinado, pasa revista a cuestiones organizativas, a la articulación entre demandas sociales y emancipación de las mujeres, invocando la necesidad de procesos de desmercantilización de las relaciones entre los seres humanos como camino hacia la emancipación política, social, racial y sexual.

Las afinidades y repeticiones en los textos traducidos dan cuenta de un cierto horizonte común, un mundo de referencias que también se pueden rastrear a lo largo de Persona y de las entrevistas y conversaciones con militantes y escritoras del período (Rodríguez Agüero, 2013). El mundo había experimentado una serie de sacudones difíciles de eludir: la transformación material que había modificado el lugar de las mujeres bajo el capitalismo y conmovido la naturalización de la división sexual del trabajo; las revoluciones tercermundistas que habían abierto una cierta sospecha sobre el eurocentrismo, que hallan ejemplo en el texto de Fanon, en las tentativas de Maschino y Maspero, en la poesía de Césaire; la puesta en cuestión del racismo, llevada a cabo en el corazón mismo del imperio desde perspectivas radicalizadas tanto por luchadores antirracistas como George Jackson, Malcom X, Angela Davis y las feministas negras y lesbianas 
que conformaron la Colectiva del Río Cambahee y dieron forma pública al Manifiesto feminista negro que reivindica la acción de Tubman y materializa una perspectiva disruptiva para las feministas blancas, heterosexuales, de clase media (1988).

Desde experiencias diversas, muchas mujeres devenían feministas al calor de una transformación en sus vidas ligada a su incorporación al mercado de trabajo y la política de una manera que implicaba, por decirlo en los términos de Williams, un cambio en la estructura del sentir, marcada por un ciclo de apertura hacia nuevas demandas: descolonización, crisis en la vida cotidiana y desnaturalización de la división sexual del trabajo y la racialización; de conmoción de las formas de percibir la sexualidad en un mundo en el cual se liberalizaron las costumbres, tal como señala Larguía: divorcios, abortos, visibilidad gay y lésbica, e incluso trans, "amor libre", son la marca de los sesenta/setenta.

Sin embargo, no se devenía feminista del mismo modo. Las marcas de clase, de ubicación, de racialización, de maneras de vivir la sexualidad atravesaban posiciones, intereses, diálogos, traducciones. Bajo un horizonte que se abría al compás de movilizaciones populares, agitación callejera y expectativas de transformación del mundo, las mujeres que devenían feministas en estas latitudes apelaban a la traducción buscando iluminaciones para sus prácticas políticas.

Una serie de nexos cruzan el mundo de la traducción con el del activismo feminista y la militancia política, entre las activistas, entre los textos traducidos (muchas veces los mismos). Larguía encarna esos cruces. Habitante de varios mundos, había nacido en Rosario, pero vivía en Cuba y había escrito un texto, que circuló en diferentes versiones: la revista Partisans y la versión argentina traducida por Lugones. También el libro editado por Henault.

Henault compartió con Vainstok la inquietud por el lugar de las mujeres en distintos procesos revolucionarios: la revolución francesa, la rusa, la china, la vietnamita, la cubana, e incluso la experiencia peronista, que ambas consideraban como una transformación revolucionaria en la vida de las mujeres en Argentina.

Randall no era una excepción para su generación. Residente durante años en los países latinoamericanos, la estadounidense compartía con muchas personas de su tiempo una visión sumamente crítica de las políticas de su país en Nuestra América y Vietnam. Su involucramiento en distintos procesos revolucionarios, su interés en "la revolución en la revolución" le hacía pensar que la emancipación de las mujeres solo sería posible en el marco de una sociedad socialista que alentara y estimulara la posibilidad de transformar no sólo las relaciones sociales de producción, sino las relaciones de los seres humanos entre sí y con la naturaleza.

\section{Conclusiones}

Determinadas por las condiciones de existencia de su tiempo, de transformaciones en el capitalismo tardío y de internacionalización desde abajo de la lucha anticolonial, las mujeres vieron conmoverse sus condiciones de existencia. A ello se sumó la extensión de la posibilidad de decidir de manera autónoma sobre las consecuencias reproductivas de la sexuación. Ese conjunto de procesos impulsó un debate sobre políticas sexuales de dimensiones hasta entonces desconocidas, que fue acompañado por el devenir feministas de miles de mujeres a lo largo y ancho del mundo.

Tal devenir estuvo marcado, desde luego, por la pertenencia de clase, la racialización, la ubicación espacial, la orientación del deseo en un tiempo de densa presencia de las izquierdas en el escenario político del continente. El marxismo se presentaba como una herramienta indispensable para el debate, no sólo respecto del capitalismo, sino acerca de la colonialidad e incluso de las consecuencias políticas de la sexuación humana. Engels era entonces, probablemente tanto como de Beauvoir, una referencia obligada. De allí la extensión internacional del debate a propósito de las consecuencias de la división sexual del trabajo. Un delgado hilo une preguntas y autoras/es en Estados Unidos, Italia, Canadá, Francia, Cuba, Argentina, Brasil. La afinidad entre los argumentos de Benston, Morton, Larguía, Dalla Costa y James, Dupont (Delphy) es algo más que un asunto de casualidades (Benston, 1969; Dalla Costa \& James, 1972; Dupont, 1972). Sus afinidades y disputas se ligan a sus ubicaciones diferenciales, a sus experiencias, a sus necesidades organizativas, pero también a un sostenido diálogo internacionalista que precipita en traducciones que por entonces circulaban (desde luego de manera desigual) en dirección norte-sur, pero también sur-norte. 
La mayor parte de ellas compartía un horizonte político que hace explícito Margaret Randall en la introducción de su conocido libro, Las mujeres: se trataba de entablar un combate con el feminismo liberal a la vez que enfrentar las limitaciones de las organizaciones partidarias de la izquierda. Desde luego, algunas priorizaban la resolución de los problemas y demandas más inmediatos, como las guarderías y los arreglos de la vida cotidiana, mientras otras buscaban fundir "la revolución como lucha de clases y como parte integral de esa lucha, la liberación de las mujeres” (Randall, 1969, p. 11).

La convocatoria a debatir que Las mujeres dicen basta pone en circulación es algo más que una inquietud individual. Obedece a la necesidad urgente de dar respuestas a un asunto inquietante: los efectos que sobre las vidas de las mujeres tiene la división sexual del trabajo, y en el campo de las políticas de las izquierdas, los efectos del conservadurismo de la moral sexual. Del mismo modo que las italianas ligadas a Potere Operaio, un grupo de izquierda extraparlamentaria al que perteneció Mariarosa Dalla Costa que por entonces integraba Lotta femminile, elaboraban una crítica de la familia y la forma naturalizada de la división sexual del trabajo, Morton y Larguía compartían la preocupación por los efectos de la división sexual del trabajo. La canadiense, movida por el deseo de transformar su propia sociedad desde una organización trotskista; la argentino-cubana, sumergida en el clima de la revolución, insistía en la cuestión del liberalismo y su asociación a la revolución sexual denunciando la mercantilización del sexo y su funcionalidad a la lógica del capitalismo.

Randall y Larguía se hallaban ligadas al proceso de la revolución cubana, como lo estaba Henault. Larguía dialogaban con quienes sostenían Partisans, del mismo modo que Otilia Vainstok deseaba hacer posible el intercambio entre feministas y revolucionarios/revolucionarias, preocupada por incorporar el asunto del feminismo al ritmo del tiempo febril que vivía.

El campo de articulaciones entre economía, política y cultura se hallaba entonces impregnado de una manera particular por la presencia de organizaciones e ideas procedentes del amplio y complejo campo de la tradición marxista. Las feministas argentinas recurrieron de distintas formas a esas herramientas teóricas en las producciones propias, a la vez que se esforzaron por dialogar con las producciones de las luchadoras feministas que, en el norte, procuraban debatir a su vez con un amplio abanico de militantes y pensadores/as ubicados en distintas posiciones en un tiempo de honda conmoción de certezas.

Publicar, debatir, traducir tampoco hubiese sido posible sin Divinsky, Goligorsky, Spivacow, todos ellos comprometidos con la izquierda en sus distintas versiones. Recuperar esos lazos, iluminar las maneras de esos diálogos, sus tensiones y dificultades, pero también sus afinidades, forma parte de la tentativa de hacer más densa la trama de nuestras genealogías como feministas del sur, de dar cuenta de un modo más matizado de sus avatares, de recuperar sus especificidades.

\section{REFERENCIAS}

Ander Egg, E. (1972). Opresión y marginalidad de la mujer en el orden social machista. Humanitas.

Andújar, A., D’Antonio, D., Grammático, K., Gil Lozano, F., et al. (2005). Historia, género y política en los 70 . Feminaria

Andújar, A. (2009). De militancias, minifaldas y revoluciones. Luxemburg.

Baschetti, R. (2018). Lugones Susana. Militantes del Peronismo Revolucionario uno por uno. http://www. robertobaschetti.com/biografia///170.html

Basualdo, E. (2006). Estudios de historia económica argentina. Siglo XXI.

Bellucci, M. \& Teumer E. (2018). Desde la Cuba revolucionaria, feminismo y marxismo en la obra de Isabel Larguía y John Dumoulin. CLACSO. https://doi.org/10.2307/j.ctvn96g7b

Ciriza, A. (2013) Tras los pasos de la experiencia política de los sectores subalternos y las mujeres. Las determinaciones del/los tiempos (cronos y kairós) las corporalidades, los lugares/el lugar. En, Actas de las XXIII Jornadas de Investigación y Postgrado de la Sectyp-UNCUYO, EDIUNC.

Ciriza, A. (2018). Tras los pasos de experiencias y genealogías feministas en la Argentina de los años 70. Una revisión situada. En, A. Ciriza. (Org.), Tiempos disruptivos. Lecturas sobre la centralidad de la política en los 70, (pp. 97-126). EDIUNC.

Colectiva del Río Cambahee. (1988). Una declaración feminista negra. En, C. Moraga \& A. Castillo, (Comp.), Esta puente mi espalda, (pp. 172-184). ISM.

Dalla Costa, M. \& James, S. (1972) Las mujeres y la subversión de la comunidad. Siglo XXI. 
Dos Santos, E. (1983). Las mujeres peronistas. CEAL.

Dupont, C. (1973). El enemigo principal. En, C. Rochefort et al., La liberación de la mujer: año cero. Granica. Fanon, F. (1973). Los condenados de la tierra. FCE.

Fanon, F. (1973). Los condenados de la tierra. FCE.

Federici, S. (2018). El patriarcado del salario. Tinta Limón.

Felitti, K. (2012). La revolución de la pildora: sexualidad y política en los sesenta. Edhasa.

Fernández Buey, F. \& Riechmann J. (1994). Redes que dan libertad: introducción a los nuevos movimientos sociales. Paidós.

Grammático, K. (2012). Mujeres montoneras. Una historia de la Agrupación Evita 1973-1974. Luxemburg.

Guichard, B. et al. (2009). François Maspero et les paysages humain. La fosse aux ours.

Henault, M. (2012). Nueva Mujer. Disponible en: https://revistafeministabrujas32atem.blogspot.com/2012/o2/nuevamujer-mirta-henault.html

Henault, M. (s.f.). La mujer y los cambios sociales. En, M. Henault, P. Morton \& I. Larguía. Las mujeres dicen basta, (pp. 13-40). Nueva Mujer.

Henault, M., Morton, P., \& Larguía, I. (s.f.) Las mujeres dicen basta. Nueva Mujer.

Kennedy, J. F (1961) Discurso del Presidente Kennedy sobre América Latina, 13 de marzo de 1961, Alianza para el Progreso. Documentos Básicos. 2-8. http://www.memoriachilena.gob.cl/archivos2/pdfs/MCo016012.pdf

Kossok, M. (1983). Historia comparativa de las revoluciones de la época moderna. Problemas metodológicos y empíricos de la investigación. En, M. Kossok, Las revoluciones burguesas, (pp. 11-58). Crítica.

Larguía, I. (s.f.). La mujer. En, M. Henault, P. Morton \& I. Larguía. Las mujeres dicen basta, (pp. 71-128). Nueva Mujer.

Larguía, I. \& Dumoulin, J. (1988). Hacia una concepción científica de la emancipación de la mujer. En, M. Bellucci y E. Theumer (Org.) Desde la Cuba revolucionaria: Feminismo y marxismo en la obra de Isabel Larguía y John Dumoulin. (pp. 117-148) CLACSO. https://doi.org/10.2307/j.ctvt6rmbs.17

Lenine, V. I. (1919). La grande initiative. L'hérö̈sme des ouvriers de l'arrière. A propos des 'Samedis Communistes'. CEuvres, Tomo 29, (pp. 413-438). Disponible en: https://www.marxists.org/francais/lenin/works/1919/06/ vil19190628.html

Mandel, E. (1979). El capitalismo tardío. Era.

Martínez, P. (2009). Género, política y revolución en los años setenta. Las mujeres del PRT-ERP. Imago Mundi.

Marx, K. (1973). El Capital, Tomo I. Editorial Cartago.

Mitchell, J. (1969). Las mujeres, la revolución más larga. En, M. Randall, Las mujeres, (pp. 67-104), Siglo XXI.

Morton, P. (s.f.). El trabajo de la mujer nunca se termina. En, M. Henault, P. Morton \& I. Larguía. Las mujeres dicen basta, (pp. 41-70). Nueva Mujer.

Oddone, M. E. (2001). La pasión por la libertad: memorias de una feminista. Ediciones Colihue Mimbipa.

Palermo, A. I. (1998). La participación de las mujeres en la Universidad. La Aljaba. Segunda época, (III), 94-110.

Pateman, C. (1995) El contrato sexual. Anthropos.

Randall, M. (1969). Las mujeres. Siglo XXI.

Rapisardi, F. \& Mondarelli, A. (2001). Fiestas, baños y exilios. Los gays porteños en la última dictadura. Sudamericana.

Redondo, N. (2015). Pasado y Presente (1964-1973): entre la base de fábrica y el peronismo. En, N. Redondo, A.Urioste, E. Matta, D. Moro y D. Melchor. (Comp.) El Che y otras rebeldías II, (pp. 191-213). Editorial de la UNLapam.

Rochefort, C. (1973). La liberación de la mujer: año cero. Granica.

Rodríguez Agüero, E. (2013). Feminismos del sur. Mujeres, política y cultura en la Argentina de los '7o. Servicio de Publicaciones de la Universidad de Málaga.

Rodríguez Agüero, E. (2015). Intervenir desde los márgenes. Mujeres y feminismos en la Revista Crisis. Argentina, 1973-1973. Nomadías, (19), 105-128. https://doi.org/10.5354/0719-0905.2015.36765

Seoane, M. (2014). Bravas. Alicia Eguren de Cooke y Susana Pirí Lugones. Sudamericana.

Trebisacce, C. \& Torelli, M. L. (2011). Memorias feministas, ni escritas ni contadas, guardadas. Metiendo las narices en el archivo personal de una feminista argentina de los setenta. Kula. Antropología y Ciencias Sociales (4), 76-94. http://www.revistakula.com.ar/numeros-anteriores/numero-4/kula-4-6-trebisacce-y-torelli/

Vainstok, O. (1972). Para la liberación del segundo sexo. Ediciones de la Flor.

Vainstok, O. \& Henault M. (1973) Las mujeres y la revolución [fascículo]. CEAL. https://fasciculosceal.blogspot. com/2008/04/la-mujer-en-la-revolucin.html

Walsh, M. E. (7 de marzo, 1973). Carta a una compatriota. Revista Extra. http://www.magicasruinas.com.ar/revdestoo21. htm

Vassallo, A. (2005). Las Mujeres dicen basta: Feminismo y movilización política en los 70. En, Andújar, A., D’Antonio, 
D., Grammático, K., Gil Lozano, F., et al. (Comp.), Historia, Género y política en los '70, (pp. 62-89). Feminaria. Vassallo, M. (2009). Militancia y transgresión. En, Andújar, A., D’Antonio, D., Grammático, K., Gil Lozano, F., et al. (Comp.), De minifaldas, militancias y revoluciones. Exploraciones sobre los 70 en la Argentina, (pp. 19-32). Luxemburg.

Zuckerman, M. (1987). Stranger in a Strange Land: Albuquerque: Coming Back to the USA by Margaret Randall. The Women's Review of Books, 4(7), 13-14. https://doi.org/10.2307/4020003

\section{AUTORAS}

Alejandra Ciriza. Profesora, Licenciada y Doctora en Filosofía, Universidad Nacional de Cuyo. Investigadora Principal del Conicet. Directora de la Maestría en Estudios Feministas. FCPyS - UNCuyo.

Eva Rodríguez Agüero. Doctora en Ciencias Sociales por la Universidad de Buenos Aires. Secretraria general del Instituto de Estudios de Género y Mujeres, Universidad Nacional de Cuyo. Docente investigadora de la UNCuyo.

\section{Conflicto de intereses}

Las autoras no presentan conflicto de interés posible.

\section{Financiamiento}

No existió asistencia financiera de partes externas al presente artículo.

Agradecimientos

$\mathrm{N} / \mathrm{A}$ 